\title{
Uma abordagem interacionista para o estudo do papel das relações de discurso na construção conjunta de imagens identitárias
}

\section{An interactionist approach to the study of the role of discourse relations in the joint construction of identity images}

\author{
Gustavo Ximenes Cunha* \\ Universidade Federal de Minas Gerais, Belo Horizonte, MG, Brasil
}

\begin{abstract}
Resumo: Neste trabalho, apresentamos uma abordagem para o estudo do papel que as relações de discurso (justificativa, concessão, exemplificação, comentário, condição etc.) exercem na negociação de imagens identitárias (faces e territórios). Partindo, em especial, de contribuições da abordagem constituída em torno de Eddy Roulet para o estudo da organização do discurso, entendemos que o locutor, estabelecendo relações, busca produzir uma intervenção que possa ser avaliada $\mathrm{pelo} / \mathrm{s}$ interlocutor/es como suficientemente adequada, ou seja, como obediente às regras de conduta que subjazem à interação e, portanto, como não ofensiva das faces e dos territórios em jogo. Nessa perspectiva, as relações de discurso constituem um recurso que permite ao locutor tentar antecipar-se a possíveis objeções do/s interlocutor/es, bloqueando-as e, com isso, direcionando o curso do processo de coordenação de ações. À luz dessa abordagem, analisamos o excerto de uma sessão ocorrida no Supremo Tribunal Federal (STF).
\end{abstract}

Palavras-chave: Relações de discurso. Interação. Imagens identitárias.

\begin{abstract}
In this paper, we present an approach to the study of the role that discourse relations (justification, concession, exemplification, condition, etc.) play in the negotiation of identity images (faces and territories). Based on contributions from the approach built around Eddy Roulet, we understand that the locutor, establishing relationships, seeks to produce an intervention that can be evaluated by the interlocutor as sufficiently adequate, that is, as obedient to the rules of conduct that underlie the interaction and therefore as non-offensive to faces and territories. In this perspective, discourse relations are resources that allow the speaker to try to anticipate possible objections from the interlocutor, blocking them and thus directing the course of the interaction. Based on this approach, we analyzed the excerpt from a session that took place at the Supreme Federal Court (STF).
\end{abstract}

Keywords: Discourse relations. Interaction. Identity images.

* Professor da Faculdade de Letras e do Programa de Pós-Graduação em Estudos Linguísticos, Universidade Federal de Minas Gerais, Belo Horizonte, MG, Brasil; ximenescunha@yahoo.com.br. Gustavo Ximenes Cunha agradece ao CNPq a concessão da Bolsa de Produtividade em Pesquisa (nível 2), processo: 304244/2019-8. 


\section{INTRODUÇÃO}

Constitui um procedimento central de formulação do texto oral ou escrito o estabelecimento de relações entre as informações de porções textuais de extensões variadas. $\mathrm{Na}$ perspectiva interacionista em que se situa este trabalho, estabelecer relações de justificação, explicação, exemplificação, reformulação, comentário, concessão, condição e outras é parte das ações que o produtor do discurso precisa realizar para interagir com o/s outro/s, sendo, portanto, o conhecimento e o domínio dessas relações constitutivos da competência comunicativa (Morato, 2008), discursiva (Roulet, 1999) ou interacional (Pekarek Doehler, 2006; Filliettaz, 2019) dos interactantes. É por esse motivo que, nas últimas décadas, o estudo dessas relações tem despertado o interesse de abordagens que, apesar das especificidades teóricas e metodológicas que as diferenciam, podem ser globalmente caracterizadas como interacionistas ${ }^{1}$.

De modo mais ou menos explícito, essas abordagens reconhecem o papel das relações de discurso ou de algumas delas na construção conjunta de imagens identitárias ou das faces e territórios em jogo na interação ${ }^{2}$. Para Roulet (1987), por exemplo, a relação de preparação exerce uma função essencialmente ritual, já que o locutor, ao preparar um pedido verificando a disponibilidade do interlocutor em realizá-lo, tenta evitar uma recusa, ato sempre ameaçador para as faces envolvidas. Da mesma forma, Marcuschi (2002, p. 133), em estudo sobre a repetição, observa: "as R [repetições] que promovem a interação são comandadas em boa parte dos casos pelo princípio da preservação das faces". Diferentes estudiosos compreendem a relação de concessão como uma estratégia que permite ao locutor, a fim de construir uma imagem de si mais democrática ou menos autoritária, considerar na sentença subordinada o ponto de vista que refuta e que supõe corresponder ao do interlocutor e mobilizar na sentença principal o ponto de vista que sustenta (Moeschler; Spengler, 1982; Vincent; Heisler, 1999; Doury; Kerbrat-Orecchioni, 2011; Kuyumcuyan, 2016) ${ }^{3}$.

\footnotetext{
1 Algumas dessas abordagens são: Pragmática do Discurso (Roulet et al., 1985; Roulet, 1999; Roulet; Filliettaz; Grobet, 2001), Análise da Conversa (Schegloff, 2007; Schegloff; Jefferson; Sacks, 1977), Praxemática (Bres; Nowakowska, 2006, 2008; Bres; Nowakowska; Sarale, 2016), Projeto Gramática do Português Falado - grupo da organização textual-interativa (Fávero; Andrade; Aquino, 2002a, 2002b, 2006; Marcuschi, 2002; Hilgert, 2002[1990], 2002, 2006) -, Linguística Interacional (Couper-Kuhlen; Selting, 2018).

2 Para Goffman, a face corresponde ao "valor social positivo que uma pessoa efetivamente reivindica para si mesma pela linha que os outros pressupõem que ela seguiu durante um contato particular" e à "imagem do eu delineada em termos de atributos sociais aprovados" (Goffman, 1967, p. 5). Já o território diz respeito aos direitos que cada pessoa reivindica e à defesa desses mesmos direitos. Os direitos que formam o território constituem um campo de objetos físicos e simbólicos, cujos limites costumam ser preservados e defendidos (Goffman, 1973). Em Brown e Levinson (1987), as noções de face e território são reinterpretadas como face positiva e face negativa, respectivamente. Os autores definem a face negativa como "a reivindicação básica de territórios, de preservação pessoal, de direitos a não-distração — i.e. de liberdade de ação e liberdade de imposição" e a face positiva como "a autoimagem consistente e positiva ou 'personalidade' (crucialmente incluindo o desejo de que essa autoimagem seja apreciada e aprovada) reivindicada pelos interactantes” (Brown; Levinson, 1987, p. 61).

3 O papel da concessão na preservação/construção de faces é reconhecido e estudado por autores situados em outras vertentes teóricas, como a Semântica da Enunciação ou Pragmática Integrada (Ducrot, 2005; Ducrot et al., 1980) e o Funcionalismo (Neves, 1999).
} 
Porém, em nenhuma dessas abordagens para o estudo das relações de discurso, concebe-se a co-construção de imagens identitárias como algo inerente ao estabelecimento das relações ou entende-se que a compreensão pelos interlocutores de quem são uns para os outros se dá, em grande medida, no processo mesmo de estabelecer relações de contra-argumento, concessão, justificativa, preparação, explicação, reformulação, comentário, condição etc. Porque essas abordagens privilegiam a dimensão comunicativa ou informacional do discurso em detrimento de sua dimensão ritual (Cunha, 2021), subjaz a elas o entendimento de que a função primeira das relações de discurso é garantir a produção de turno compreensível pelo interlocutor ou "assegurar a intercompreensão dos enunciados" (Hilgert, 2002[1990], p. 106), permitindo aos interlocutores "resolver, contornar, ultrapassar ou impedir problemas, obstáculos ou barreiras de compreensão e, portanto, de formulação com que se deparam no desenvolvimento da construção enunciativa" (Hilgert, 2002[1990], p. 107). Consequentemente, escapa aos interesses dessas abordagens investigar em profundidade o papel dessas relações na co-construção de faces e territórios.

Por esse motivo, este trabalho, que desenvolve pesquisas que vimos realizando nos últimos anos sobre o estudo das relações de discurso na perspectiva interacionista (Cunha, 2015, 2017a, 2017b, 2019a, 2019b, 2020, 2021; Cunha; Braga, 2018; Cunha; Picinin, 2018; Cunha; Tomazi, 2019), apresenta uma abordagem para a qual são indissociáveis o processo de coordenação de ações por meio do estabelecimento das relações de discurso e o processo de construção conjunta de imagens identitárias. Partindo, em especial, de contribuições da abordagem constituída em torno de Eddy Roulet para o estudo da organização do discurso (Roulet, 1999; Roulet et al., 1985; Roulet; Filliettaz; Grobet, 2001; Moeschler, 1985; Filliettaz; Roulet, 2002), a proposta consiste em evidenciar o papel de primeira importância que as relações de discurso exercem na negociação de imagens identitárias. Sem desconsiderar os aspectos informacionais envolvidos no estabelecimento de uma relação de discurso, procuramos evidenciar de modo sistemático que o locutor, ao estabelecer uma relação, busca não só produzir um enunciado ou turno compreensível, mas também gerir as faces e os territórios em jogo. Para alcançar o objetivo colocado, este trabalho se inicia com a apresentação da noção de interação por nós adotada. Em seguida, expõe a proposta para o estudo das relações de discurso na perspectiva interacionista. Por fim, propõe a análise, nessa perspectiva, do excerto de uma sessão ocorrida no Supremo Tribunal Federal (STF), em 26 de outubro de 2017.

\section{POR UMA NOÇÃO DE INTERAÇÃO}

A proposição de uma abordagem das relações de discurso na perspectiva interacionista dos estudos da linguagem pressupõe uma definição explícita da noção de interação. Reunindo contribuições de estudiosos da interação como Goffman (1967, 1973, 2012[1986]), Kerbrat-Orecchioni (1990), Clark (1996) e Mondada (2006), Filliettaz (2014, p. 137) define a interação nestes termos:

Pode-se definir a interação linguageira como um processo temporal e sequencialmente ordenado que ocorre quando pelo menos dois indivíduos se encontram em um espaço perceptual parcialmente partilhado, no qual eles recorrem a recursos semióticos para conduzir coletivamente uma ação conjunta, ela mesma indexada em práticas sociais histórica e culturalmente cristalizadas. 
O interesse dessa definição reside no fato de ela resultar da articulação de três 'ordens de realidade'. Segundo Filliettaz $(2014,2019)$, a interação não se reduz ao encontro ou contato de dois indivíduos (ordem interpessoal), mas implica ainda a consideração dos ambientes institucionais e culturais em que o encontro ocorre (ordem sócio-histórica), bem como dos recursos semióticos por meio dos quais os interlocutores coordenam suas ações (ordem semiótica). Especifiquemos brevemente cada uma dessas ordens.

Ordem interpessoal: toda interação demanda a coordenação de ações recíprocas. Assim, para ocorrer, a interação pressupõe a partilha pelos interlocutores de um "espaço perceptual comum" (Filliettaz, 2014, p. 133) que pode ou não coincidir com o ambiente físico imediato. Nesse sentido, a noção de interação não corresponde apenas ao encontro face a face (cf. Goffman, 1967), devendo abarcar ainda as interações que ocorrem via diferentes suportes, como computadores e telefones. Além de um espaço perceptual comum, a interação pressupõe igualmente a participação dos interlocutores na realização de formas de ação coletivas, como aprender, discutir, entreter, fabricar objetos, vender-comprar produtos etc. É por isso que interagir requer "mecanismos de ajuste das contribuições respectivas" (Filliettaz, 2014, p. 133) para a realização de ações conjuntas. Esse ajuste envolve mais do que a simples troca de informações; envolve ainda a negociação das imagens identitárias (faces e territórios, cf. nota 3) ao longo da interação. É por meio da linha de conduta que segue que cada locutor revela como se vê na interação e como vê o/s outro/s. Nesse sentido, as imagens identitárias não são dadas de antemão, mas são o resultado do modo como os interlocutores coordenam suas ações.

Ordem semiótica: interagir requer recursos que possibilitem aos interlocutores a coordenação de suas ações. Um dos recursos mais importantes é a linguagem verbal ou, mais especificamente, são os diferentes planos de sua organização: a sintaxe, a semântica, a dêixis temporal, espacial e pessoal, os mecanismos enunciativos, as relações de discurso e suas marcas (conectores e tempos verbais), a estruturação global do texto, os itens fóricos de construção da cadeia referencial etc. Esses recursos correspondem ainda a outros elementos semióticos, como a prosódia, os gestos, os deslocamentos no espaço, as imagens etc. Porque interagir implica a sincronização desses vários recursos verbais e não verbais, os estudiosos da interação têm se valido cada vez mais de abordagens multimodais (Mondada, 2019; Pekarek Doehler, 2006; Filliettaz, 2014, 2015; Filliettaz; Durand; Trébert, 2018; Couper-Kuhlen; Selting, 2018; Ladilova, 2020).

Ordem sócio-histórica: a interpretação pelos interlocutores das ações que realizam não se constrói com base apenas nos mecanismos locais de ajuste das contribuições respectivas. A escolha desses mecanismos, bem como a avaliação/percepção de sua pertinência para o encontro ocorrem sob a influência da dimensão sócio-histórica da interação. Como observa Filliettaz (2014, p. 137),

Os participantes interagem não só com os indivíduos com que se encontram localmente engajados, mas também com realidades sociais que preexistem ao encontro, que o prolongam e que constituem um produto cristalizado no tempo e em contínua evolução.

Essas realidades sociais esquemáticas deram origem a diferentes conceptualizações: quadros da experiência social e regras de conduta (Goffman, 1967, 2012[1986]), cenários e scripts (Brown; Yule, 1983), tipos de atividade (Levinson, 1992), 
gêneros do texto e do discurso (Bakhtin, 2003; Bronckart, 2007), tipificação (Schultz, 1987), representação praxiológica (Filliettaz, 2000; Roulet; Filliettaz; Grobet, 2001), entre outras. Em que pesem as consideráveis diferenças teóricas que as particularizam umas em relação às outras, essas noções compartilham a finalidade de buscar circunscrever algumas das expectativas de ordem sócio-histórica que guiam os interlocutores na realização de ações. É com a mediação desse conhecimento sóciohistoricamente constituído e adquirido que eles podem categorizar a interação de que participam, definir qual linha de conduta seguir, prever qual linha poderá ser seguida pelo/s outro/s, avaliar em que medida a linha efetivamente seguida pelo/s outro/s é esperada ou inesperada (deslocada, inadequada, inovadora) etc.

As três ordens de realidade propostas por Filliettaz (2014) para conceituar a interação não devem ser entendidas evidentemente como dimensões estanques. Ao contrário, a interação se caracteriza pela articulação contínua dos aspectos emergentes da coordenação local de ações, dos recursos semióticos e dos aspectos esquemáticos de natureza sócio-histórica. É o que evidencia nosso objeto de estudo, as relações de discurso. Uma relação de comentário, reformulação, condição ou outra é um recurso semiótico que permite ao locutor realizar ações conjuntas, tentando se fazer compreendido pelo interlocutor e negociando com ele imagens identitárias. Ao mesmo tempo, a decisão do locutor por estabelecer ou não a relação implica a consideração das expectativas sócio-históricas que possui sobre o ambiente institucional em que se situa, expectativas que têm um impacto sobre o que cada participante da interação pode esperar e exigir do/s outro/s. No próximo item, abordaremos mais extensamente as relações de discurso nessa perspectiva.

\section{UMA ABORDAGEM INTERACIONISTA DAS RELAÇÕES DE DISCURSO}

Enquanto participantes competentes do processo de coordenação de ações, ou seja, enquanto (inter)agentes dotados de uma competência interacional (Filliettaz, 2019), os interlocutores sabem que produzir uma intervenção considerada inadequada pelos demais participantes da interação corresponde a seguir, aos olhos desses participantes, uma linha de conduta inesperada para o encontro, elaborando uma intervenção menos ou mais informativa do que o necessário e ameaçadora das faces e dos territórios em jogo (Roulet et al., 1985) ${ }^{4}$. Também sabem que adotar uma linha considerada inesperada implica quebrar uma "regra de conduta" ou um "guia para a ação" (Goffman, 1967) e, assim, contrariar parte das expectativas para o encontro, expectativas que, até a emergência do comportamento inesperado ou desviante, acreditavam compartilhar (Goffman, 1967, 2012[1986]; Pekarek Doehler, 2006; Filliettaz, 2014). Os interlocutores sabem ainda que esse comportamento de um dos

\footnotetext{
${ }^{4}$ A intervenção é a unidade textual constitutiva da troca (Roulet; Filliettaz; Grobet, 2001). Assim, ao longo de uma troca, os interlocutores elaboram intervenções, e cada intervenção se caracteriza por uma orientação ilocucionária própria: pergunta, pedido, informação, resposta etc. De modo geral, as intervenções se caracterizam por uma grande complexidade estrutural, o que se deve à busca de seu produtor por atender às expectativas de completude do/s interlocutor/es (Roulet et al., 1985; Roulet; Filliettaz; Grobet, 2001). Por isso, uma intervenção costuma ser constituída de um ato principal, ao qual se subordinam outros atos, intervenções e trocas. $O$ ato é a unidade mínima de análise proposta por Roulet (Roulet; Filliettaz; Grobet, 2001).
} 
interlocutores, exatamente por constituir a quebra de uma regra de conduta ou expectativa social, será interpretado pelos demais como uma ofensa (Haugh, 2015).

A natureza ofensiva do comportamento inesperado se manifesta na avaliação que os demais participantes da interação podem fazer acerca de seu responsável. Dependendo do comportamento e da expectativa que contraria, ele pode ser classificado e (des)qualificado como grosseiro, arrogante, impertinente, distante (frio), destemperado, inconveniente, invasivo, desajeitado, imprudente, insensível, prolixo, lacônico, inseguro, mentiroso etc. (Kerbrat-Orecchioni, 1997; Laforest; Vincent, 2004; Jay; Janschewitz, 2008; Culpeper, 2011). Essa lista de adjetivos expressa parte da ampla paleta de valores sociais que, de modo explícito ou implícito, podem ser atribuídos ao responsável por um comportamento considerado ofensivo. E, ao manifestarem a percepção de sua quebra, expressam ainda as regras que subjazem à interação e que podem ser tanto normas comunicativas, como as máximas conversacionais de Grice (1975), quanto normas rituais, como as máximas de polidez de Lakoff (1977) e Leech (1983, 2014). Assim, se um adjetivo como prolixo manifesta a violação de uma norma comunicativa que implicitamente regulava a interação, adjetivos como arrogante e grosseiro manifestam a violação de normas rituais que também implicitamente regulavam a interação. Mas, em ambos os casos, aquele que é assim qualificado tem sua face atacada ou comprometida em algum grau (Lakoff, 1977; Culpeper, 2011; Leech, 2014).

Diferentes reações podem decorrer da quebra de uma regra de conduta, além da avaliação mencionada. Ao terem (parte de) suas expectativas contrariadas, interpretando como inesperado o comportamento de um dos interlocutores, os demais podem tentar compatibilizar esse comportamento com a imagem que têm da interação, a fim de inseri-lo no fluxo dos acontecimentos. Podem também buscar reenquadrar a interação, reavaliando-a como mais ou menos tensa ou formal, e, com isso, reinterpretar o tipo de elo que os liga ao participante que agiu de modo inesperado. Podem ainda auxiliá-lo a retomar a linha de conduta esperada, amenizando os danos para a face do próprio participante. Ou podem apenas evidenciar sua percepção de que uma regra de conduta foi violada, atribuindo a esse participante o dever de se justificar/explicar/desculpar, com o fim de recompor as faces ou os territórios atacados (Goffman, 1967, 1973, 2012[1986]; Vion, 1992; Burger, 1999, 2004; Jacquin, 2014).

Essas (re)ações dos demais participantes da interação têm a finalidade de manter a interação em curso e se materializam em objeções ${ }^{5}$ cujo efeito é complexo. Se, de um lado, permitem tentar mitigar os danos causados pela ofensa, de outro tornam o participante em falta consciente da ofensa que cometeu. Por isso, a produção de uma objeção atribui aos interlocutores os papéis de ofensor e de ofendido, papéis que influenciam o modo como coordenarão as ações recíprocas, a partir da objeção. Esses papéis correspondem a identidades momentânea e ocasionalmente assumidas pelos interlocutores, em razão do modo como agem. Assim, o papel de ofensor designa aquele que é alvo de uma objeção (ou a quem é atribuído um modo de agir inesperado, desviante), ao passo que o de ofendido designa aquele que realiza a objeção. As

\footnotetext{
${ }^{5}$ Como expusemos em Cunha (2019a, 2020), essas objeções se materializam - ou se textualizam - de três formas: 1) abertura pelo interlocutor de trocas secundárias ou subordinadas em que pede esclarecimentos ao locutor; 2) elaboração pelo interlocutor de reações negativas (refutações) (Cunha, 2019b); 3) elaboração pelo interlocutor de uma intervenção que subordina a troca em curso.
} 
objeções, portanto, são uma manifestação pública de que, aos olhos do ofendido, um dos interlocutores cometeu uma ofensa e constituem o início de um processo local de reparação dessa ofensa (face work (Goffman, 1967)) ${ }^{6}$.

Nessa perspectiva, as relações de discurso surgem como um elemento central do processo de coordenação de ações. Estabelecendo relações de concessão, exemplificação, comentário, justificativa, condição e outras, o locutor busca produzir uma intervenção que, em virtude do modo como representa a interação em curso e, por isso mesmo, das expectativas que acredita partilhar com o/s interlocutor/es, possa ser avaliada por este/s como suficientemente adequada. Ao elaborar sua intervenção sustentando afirmações com justificativas e explicações, trazendo exemplos, estabelecendo condições para a realização de ações, reformulando porções do texto, esclarecendo o tópico de sua intervenção, reconhecendo méritos no ponto de vista adversário etc., o locutor busca mostrar ao/s interlocutor/es que ele segue uma linha de conduta esperada ou obediente às regras de conduta que subjazem ao encontro e, portanto, não ofensiva.

Desse modo, as relações constituem um recurso que permite ao locutor tentar antecipar-se a possíveis objeções do/s interlocutor/es, bloqueando-as e, com isso, direcionando o curso do processo de coordenação de ações (Cunha, 2020). Evitando objeções, o locutor impede que a ele seja atribuído o papel de ofensor, afastando as implicações negativas para as imagens identitárias que decorrem dessa atribuição. Contudo, como as expectativas sobre como agir são apenas parcialmente compartilhadas, o locutor não tem garantias de que as relações que estabelece serão, de fato, capazes de evitar todas as objeções que o/s interlocutor/es possa/m lhe direcionar, o que torna esse processo amplamente dinâmico e dependente do modo como os participantes da interação coordenam suas ações.

Nessa perspectiva, reconhece-se que as relações de discurso são parte essencial da dinâmica interacional, exercendo papel importante na co-construção de imagens identitárias. Afinal, o modo como os interlocutores coordenam suas ações recíprocas, estabelecendo ou deixando de estabelecer relações de discurso, evidencia o grau de compartilhamento das representações sobre o que seja a interação em curso, sobre o que seus participantes podem ou não dizer/fazer e sobre quais regras de conduta devem seguir. As relações de discurso constituem, assim, um recurso de que se valem para tentar evitar objeções, negociar (ajustar, questionar) suas expectativas e construir conjuntamente imagens identitárias, atribuindo-se, ao longo da interação, os papéis de ofensor e ofendido. Ao mesmo tempo, elas constituem um recurso precioso de que o analista dispõe para apreender o que se passa ao longo do processo de coordenação de ações. No próximo item, a abordagem delineada neste item será utilizada na compreensão do papel que as relações de discurso exercem em uma interação no STF.

\footnotetext{
${ }^{6}$ Os papéis de ofensor e ofendido devem ser entendidos como papéis praxiológicos (Roulet; Filliettaz; Grobet, 2001) ou interacionais (Burger, 1999, 2004) e não preveem a emergência ou manifestação de emoções no discurso (espanto, perplexidade, raiva, irritação, constrangimento, indignação, compaixão, medo, vergonha etc.). Para nós, a compreensão da relação entre produção de objeções, assunção dos papéis de ofensor e de ofendido e emergência de emoções no discurso depende da articulação de três fatores: i) a importância que os interlocutores (mas, em especial, o ofendido) dão à regra de conduta violada, ii) a forma como o ofendido realiza - textualiza - a objeção e iii) o ambiente institucional em que estão inseridos (Goffman, 1967; Rinn, 2008; Langlotz; Locher, 2017; Cunha, 2019a, 2020). O alcance dessa compreensão deverá constituir objeto de estudos futuros.
} 


\section{O ESTABELECIMENTO DE RELAÇÕES DE DISCURSO EM SESSÃO DO SUPREMO TRIBUNAL FEDERAL (STF)}

Neste item, analisaremos, à luz da proposta delineada no item anterior, o excerto de uma sessão do STF que ocorreu em 26 de outubro de 2017 e que tratou de uma ação para validar a extinção do Tribunal de Contas dos Municípios do Ceará ${ }^{7}$. No excerto, os interlocutores são os Ministros Gilmar Mendes e Luís Roberto Barroso (doravante GM e LRB, respectivamente). Ao longo do excerto, há intervenções pontuais da Ministra Carmen Lúcia. A escolha dessa interação se justifica pelo ambiente fortemente institucional e amplamente conhecido em que ocorre (sessão plenária do STF) e pelo fato de nela ficar evidente que o estabelecimento de relações de discurso pelos interlocutores permite a cada um, ao mesmo tempo, tentar salvar a própria face e/ou o próprio território e justificar os ataques à face e/ou ao território do outro, revelando e negociando, de modo conflituoso, as expectativas apenas parcialmente compartilhadas sobre a interação em curso.

A interação entre GM e LRB se inicia com uma troca de acusações indiretas em que cada ministro critica o estado de origem do outro. GM critica o Rio de Janeiro, estado de origem de LRB, ao passo que LRB critica o Mato Grosso, estado de origem de GM. Essa troca de acusações, reduzidas a atos isolados, se estende até o ato (08), a partir do qual as críticas passam a ser mais diretas e desenvolvidas.

GM: (01) a prova de que falta criatividade ao administrador é o caso do Rio de Janeiro \\(02) gente/ citar o Rio de Janeiro como exemplo/

LRB: (03) devem achar que é Mato Grosso\

GM: (04) não não.. (05) é o Rio de Janeiro mesmo-

LRB: (06) onde tá todo mundo PREso \\

GM: (07) éh ah não (08) no no Rio não estão//

LRB: (09) não não sim (10) aliás nós prendemos/. (11) tem gente que solta \\

Com a intervenção formada pelos atos (09-11), LRB responde à pergunta feita por GM em (08): 'no no Rio não estão//'. Em sua resposta, LRB sustenta o ato '(09) não não sim [está todo mundo preso]' com o argumento formado pelos atos (10-11): '(10) aliás nós prendemos/. (11) tem gente que solta \\'. O uso do aliás sugere que, para LRB, esse argumento deve ser entendido como acessório, não devendo ser retomado pelo interlocutor na sequência da troca. No interior do argumento, o ministro estabelece uma relação de contra-argumento entre o ato (11) e a informação expressa no (10), o que pode ser explicitado por um conector contra-argumentativo: '(10) aliás nós prendemos/. (11) [mas] tem gente que solta \\'. Com essa relação, LRB tenta elaborar uma intervenção suficientemente adequada, bloqueando objeções que

\footnotetext{
7 O excerto encontra-se no Anexo deste trabalho e foi objeto de análise em Cunha (2019a). Na transcrição desse excerto, adotamos as seguintes convenções: / - \(contorno melódico continuativo ascendente, plano ou descendente), $/ /=\backslash \backslash$ (contorno melódico conclusivo ascendente, plano ou descendente), ... (pausa mais ou menos longa), : :: (alongamento mais ou menos acentuado), sublinhado (recobrimento de fala), [ ] comentário, risos, mudança de elocução ou de amplitude, ( ) palavra cuja compreensão é incerta, (X) sílaba incompreensível (Roulet; Filliettaz; Grobet, 2001, p. 407). No excerto, a numeração indica a segmentação do texto em atos. Informações detalhadas sobre o processo de que a sessão faz parte podem ser obtidas em: http://portal.stf.jus.br/processos $/$ detalhe.. sp? incidente $=5249161$.
} 
poderiam ser derivadas da conclusão a que leva o ato (10), como: 'Se vocês prendem condenados da Justiça, então quem os solta?'.

Em seguida, GM reage produzindo esta intervenção: '(12) veja veja o caso/. (13) solta cumprindo: a Constituição \\(14) quem gosta de prender// (15) vossa excelência quando chegou aqui/.. (16) éh soltou o Zé Dirceu:: \.. [Hah]’. Ao iniciá-la, o ministro indica, com o ato (12) ('veja veja o caso/.'), que não se deterá nas informações expressas nos atos (10-11) da intervenção de LRB, sugerindo que a relação de argumento marcada pelo 'aliás' contribuiu para tornar essa intervenção adequada. Porém GM logo se interrompe e, nos atos (13-16), revela sua compreensão de que, no argumento trazido pelo interlocutor, este indiretamente se elogia ('(10) aliás nós prendemos/.') e o critica ('(11) tem gente que solta \\').

Com o ato (13) ('solta cumprindo: a Constituição \’), GM faz uma objeção à crítica indireta que recebeu, indicando que a intervenção de LRB é, para ele, inadequada por não informar suas motivações para soltar réus. Assim, a objeção sugere que, para GM, a intervenção do interlocutor é inadequada tanto do ponto de vista informacional (faltam informações), quanto do ritual (a crítica é injustificada). A essa objeção GM acrescenta, nos atos (14-16), outra ao autoelogio de LRB ou à sua eficiência em prender condenados. Essa objeção é complexa, porque, primeiro, questiona a afirmação de LRB ((10) 'nós prendemos') por meio da pergunta '(14) quem gosta de prender//' e, em seguida, traz em (15-16) uma evidência (a libertação do exministro José Dirceu) para sustentar a conclusão implícita de que, ao contrário do que afirma LRB, este não gosta de prender. Desse modo, GM elabora nessa objeção uma troca lacunar em que a conclusão implícita e os atos (15-16) formam a resposta à pergunta feita em (14):

A: Quem gosta de prender? [ato 14]

B: Não pode ser vossa excelência [conclusão implícita] [porque] vossa excelência quando chegou aqui soltou o Zé Dirceu [atos 15-16]

Com a intervenção formada pelos atos (13-16), GM evidencia, portanto, que, de seu ponto de vista, LRB violou o modo como deveria agir, produzindo uma intervenção inadequada, por ser menos informativa do que o requerido e por colocar em risco as faces em jogo. Agindo dessa forma, GM atribui o papel de ofendido a si e o de ofensor ao interlocutor.

Embora a objeção de GM seja complexa, LRB, ao tomar a palavra, revela que a julgou inadequada. $\mathrm{O}$ ministro evidencia esse julgamento por meio do ato (17) ('porque recebeu inDULto do presidente da República \\'), que constitui uma explicação de suas motivações para libertar José Dirceu. Por meio dessa explicação, LRB faz uma objeção à crítica de GM, revelando que a libertação de José Dirceu, dadas as restrições que pesam sobre os ministros do STF, não foi motivada por uma vontade própria ou por uma decisão pessoal. Com essa objeção, LRB denuncia a adoção de uma linha de conduta inadequada pelo interlocutor, que deveria considerar as motivações dos colegas ministros para a realização de julgamentos, e reivindica o papel de ofendido, apontando a ofensa de que foi alvo. Com isso, LRB busca redistribuir os papéis de ofensor e ofendido. Se GM, ao formular a intervenção (12-16) tivesse se valido do argumento levantado por LRB, bloquearia a realização dessa objeção, como revela a troca a seguir, na qual a função do ato (17) seria apenas a de confirmar um 
argumento previamente expresso (trecho em itálico) e não a de trazer um argumento para revelar a incompletude da intervenção do interlocutor.

GM: (12) veja veja o caso/. (13) solta cumprindo: a Constituição \\(14) quem gosta de prender// (15) vossa excelência quando chegou aqui/.. (16) éh soltou o Zé Dirceu:: $\backslash$. [ [Hah] porque recebeu indulto do presidente da República

LRB: (17) porque recebeu inDULto do presidente da $\underline{\text { República } \backslash}$

$\mathrm{Na}$ sequência, com a intervenção (18-20), GM refuta o argumento trazido por LRB em (17), evidenciando sua avaliação de que esse argumento é incompleto: '(18) não não não (19) vossa excelência disse/. (20) vossa excelência julgou os embargos infringentes /'. Do ponto de vista de GM, expresso nessa intervenção, uma evidência de que a libertação de José Dirceu se deu por uma decisão pessoal de LRB foi este ter julgado os embargos infringentes de Dirceu. ${ }^{8}$. Com isso, GM revela sua percepção de que LRB, ao não assumir a responsabilidade por um julgamento, contraria uma expectativa que subjaz à interação de que participam e, assim, ofende os demais interlocutores. Se LRB, por meio, por exemplo, de uma relação de contra-argumento (concessão), tivesse se referido aos embargos infringentes, a refutação de GM não seria possível ou precisaria ser formulada de outra maneira. Por isso, como revela esta troca, a sentença concessiva (trecho em itálico) faz a mesma refutação perder sua eficácia:

LRB: Embora eu tenba julgado os embargos infringentes, José Dirceu recebeu inDULto do presidente da República \}

GM: (18) não não não (19) vossa excelência disse/. (20) vossa excelência julgou os embargos infringentes/

Após a refutação de GM, LRB insiste no argumento de que a libertação de José Dirceu foi motivada por um indulto, enquanto GM persevera na refutação do argumento.

LRB: (27) então gostaria de dizer que José Dirceu foi SOLto/

GM: (28) não não/

LRB: (29) por inDULto da presidente da República \}

GM: (30) vossa excelência julgou \

LRB: (31) não/

GM: (32) vossa excelência julgou (demais)/

Nesse trecho formado pelos atos (27-32), a manutenção por GM de uma linha refutativa só é possível porque LRB, na formulação de suas intervenções, se limita a reiterar o argumento do indulto da presidência (ato 29) e a se opor à pertinência da refutação (ato 31). Como LRB não estabelece nenhuma relação de discurso, por meio da qual justificasse suas intervenções, ele permite que GM, em (32), insista em sua linha de conduta ('vossa excelência julgou (demais)/'), desempenhando o papel de ofendido e atribuindo ao outro o de ofensor. Nesse sentido, as sucessivas objeções de GM à fala de LRB constituem evidências de que, para o primeiro, as intervenções produzidas até o momento pelo segundo, todas reduzidas a poucos atos, são inadequadas para o

\footnotetext{
${ }^{8}$ Embargos infringentes são um tipo de recurso que é interposto pelo réu e que se baseia na falta de unanimidade das decisões colegiadas do STF (Barros; Lemos, 2018).
} 
processo de coordenação de ações em curso, violadoras de regras de conduta e, portanto, ofensivas.

Por isso, a partir do ato (33), LRB passa a adotar uma linha de conduta distinta e a elaborar intervenções mais complexas, que possam atender à exigência de completude de GM, obrigando-o a mudar sua linha e, assim, a abandonar o argumento do protagonismo de LRB na libertação de José Dirceu. O que LRB busca, desse modo, é produzir intervenções que impeçam GM de realizar novas objeções e atribuir a ele novamente o papel de ofensor.

Nesse novo modo agir, LRB produz uma longa intervenção (atos 33-49) que possui uma natureza metadiscursiva, na medida em que gira em torno da impertinência do comportamento do interlocutor. Com essa intervenção, o ministro realiza objeções que focalizam, sobretudo, o aspecto ritual da interação, revelando que, de seu ponto de vista, GM viola expectativas sobre como agir em uma sessão do STF e, por isso, age de forma ofensiva.

LRB: (33) e vossa excelência tá fazendo um comício que não tem nada que ver com extinção de tribunal de contas no CeaRÁ \\

GM: (34) tem $\backslash \backslash$ tem $\operatorname{sim} \backslash \backslash$

LRB: (35) vossa excelência tá queixoso (36) porque perdeu o caso dos precatórios. (37) e tá ocupando tempo do plenário com assunto que NÃO é pertinente/

GM: (38) nós escutamos vossa excelência/

LRB: (39) pra destilar esse Ódio constante que vossa excelência tem. (40) e agora o dirige contra o Rio/.. (41) vossa excelência devia ouvir a última música do Chico Buarque/.. (42) a RAIva é filha do medo e MÃE da covardia \(43) vossa excelência fica destilando ódio o tempo inteiro/ (44) não julga/ (45) não fala coisas racionais articuladas/ (46) sempre fala coisa contra alguém/ (47) tá sempre com ódio de alguém/ (48) tá sempre com raiva de alguém/ (49) use um argumento... o mérito do argumento...

Entrecortada por duas objeções de GM (atos 34 e 38), a intervenção de LRB se apoia em quatro atos centrais:

(35) vossa excelência tá queixoso

(37) e tá ocupando tempo do plenário com assunto que NÃO é pertinente/

(44) não julga/

(49) use um argumento... o mérito do argumento...

Os demais atos trazem argumentos com que LRB visa impedir que GM refute ou invalide os atos centrais por meio de objeções e, dessa forma, o acuse de produzir uma intervenção inadequada. O objetivo é, portanto, levar GM a adotar uma linha de conduta diferente da seguida até o momento. Por exemplo, para que GM não refute a acusação de que ele 'não julga/', ato (44), LRB traz uma série de justificativas coordenadas nos atos (45-48), o que pode ser evidenciado com o conector porque:

(44) não julga/ [porque] (45) não fala coisas racionais articuladas/ (46) sempre fala coisa contra alguém/ (47) tá sempre com ódio de alguém/ (48) tá sempre com raiva de alguém/ 
Essas justificativas impedem que GM, no desenvolvimento da troca, faça objeções como: ‘Por que eu não julgo?'. E, dada a coordenação de quatro argumentos sobre sua agressividade, diminuem as chances de ele fazer objeções sobre essa agressividade.

Após a longa intervenção de LRB, GM não interpõe nenhuma objeção às críticas que lhe são endereçadas, não avaliando a intervenção do colega como ritualmente inadequada por atacar sua face. Quando a ministra Carmen Lúcia intervém no ato (50), solicitando aos colegas que retomem o julgamento relativo ao Tribunal de Contas dos Municípios do Ceará ('ministros/.. eu pediria que a gente voltasse/ ah voltasse ao julgamento do caso/ por favor $\backslash$ '), GM não se defende das críticas, mas anuncia que pretende insistir na questão dos embargos infringentes ('(52) só eu só queria lembrar que os embargos infringentes do José Dirceu foram decididos aqui.

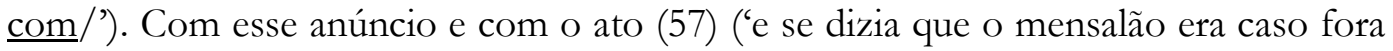
da curva/'), o ministro evidencia que, para ele, a intervenção de LRB, ainda que formada por vários argumentos, é inadequada, por não justificar ou esclarecer o julgamento dos embargos infringentes. Assim, a retomada por GM da mesma objeção que fez previamente revela que, para ele, o modo de agir de LRB contraria a expectativa segundo a qual um ministro do Supremo, se instado por um colega a se justificar, deve realizar essa ação, sendo, por isso, ofensivo.

Porque GM indica que retomará a linha acusatória contra LRB, este produz uma nova longa intervenção formada pelos atos (58-76) em que tenta adotar uma linha de conduta que possa ser considerada adequada pelo interlocutor, desenvolvendo o argumento de que quem decidiu pela concessão do indulto de José Dirceu não foi ele, mas o STF, com base em decreto aprovado pela Presidência da República.

LRB: (58) Zé Dirceu permaneceu preso/ sob minha jurisdição/ (59) inclusive recorri à prisão domiciliar (60) porque achei imprópria/ (61) e concedi a ele indulto com base no decreto/ eeh.. aprovado pela presidente da República/ (62) porque ninguém é melhor nem pior do que ninGUÉM/ (63) e portanto apliquei a ele a lei que vale para todo mundo/ (64) quem decidiu foi o Supremo/ (65) aliás não fui eu/ (66) porque o Supremo tem onze ministros $\backslash(67)$ e portanto a maioria entendeu

GM: (68) então não venha/ então não venha/

LRB: (69) que não havia o crime \(70) e depois ele cumpriu a pena/ (71) e só foi SOLto. por inDULto/ (72) e mesmo assim permaneceu preso/ (73) porque estava preso por determinação da $13^{a}$ Vara Criminal de Curitiba \ (74) e agora só está solto (75) porque a SeGUNda turma determinou que ele fosse solto \(76) portanto não transfira pra mim. esta parceria que vossa excelência tem com a leniÊNcia em relação à criminalidade do colarinho branco $\backslash \backslash$

Nessa intervenção, LRB, após as sucessivas avaliações negativas de GM quanto à completude de suas intervenções, defende-se trazendo não apenas o que considera uma evidência da lisura de seu julgamento, mas quatro, que são expressas nestes atos centrais:

(61) e concedi a ele indulto com base no decreto/ eeh.. aprovado pela presidente da República/

(63) e portanto apliquei a ele a lei que vale para todo mundo/ 
(67) e portanto a maioria entendeu

(76) portanto não transfira pra mim. esta parceria que vossa excelência tem com a leniÊNcia em relação à criminalidade do colarinho branco $\backslash \backslash$

$\mathrm{Na}$ busca por limitar as chances de objeções do interlocutor quanto à completude da intervenção que produz, mostrando-se disposto a prestar os esclarecimentos solicitados e não mais desempenhar o papel de ofensor, LRB sustenta cada uma dessas evidências com argumentos, o que faz com que essa grande intervenção seja estruturada em quadro porções textuais maiores, cada uma tendo como núcleo uma das evidências mencionadas. É o que demonstramos com a intervenção formada pelos atos (63-66):

(63) e portanto apliquei a ele a lei que vale para todo mundo/ (64) quem decidiu foi o Supremo/ (65) aliás não fui eu/ (66) porque o Supremo tem onze ministros $\backslash$

Se LRB se limitasse a produzir o ato central (63), GM poderia dar sequência à troca desta forma:

LRB: (63) e portanto apliquei a ele a lei que vale para todo mundo/

GM: mas vossa excelência não decide sozinho, não tem poder para, sozinho, aplicar uma lei.

Por meio dessa objeção, GM acusaria LRB, com a produção do ato (63), de atacar os demais ministros, por reivindicar um protagonismo na aplicação da lei. Ao mesmo tempo, atacaria tanto a face de LRB, já que a objeção constitui uma crítica, quanto seu território, já que a objeção revela as limitações de suas atribuições enquanto ministro do STF. Para evitar essa objeção e suas implicações para as imagens identitárias em jogo, LRB estabelece uma relação de argumento por meio da qual subordina ao ato (63) as informações expressas em (64-66). Nesses atos, ele especifica que quem decide é o Supremo (ato 64), não é apenas ele (ato 65), são seus onze ministros (ato 66).

Em cada uma das quatro porções textuais de que a intervenção (58-76) é formada, chama a atenção a frequência de relações de argumento marcadas, em particular, por ocorrências do conector porque. Cada ocorrência introduz uma justificativa ou explicação para a afirmação em que se liga, e cada justificativa constitui uma objeção que LRB supõe que GM poderá lhe endereçar sobre a afirmação. Ao agir dessa forma, LRB tenta bloquear as objeções, buscando levar GM a aceitar a completude de sua intervenção e, consequentemente, a pertinência de sua (nova) linha de conduta.

Além da organização interna de cada porção textual formada por uma evidência (ato central) e por argumentos, cabe examinar as relações de discurso que LRB estabelece entre essas porções. Com exceção do ato (61), em que LRB retoma informação dada nos atos (17) ("porque recebeu inDULto do presidente da República \\') e (29) ('por inDULto da presidente da República \’'), os atos (63), (67) e (76) são introduzidos pelo conector portanto, típico introdutor de conclusão (Guimarães, 1987). O uso reiterado desse conector permite ao ministro sinalizar um processo de subordinações retroativas por meio do qual apoia cada nova conclusão nas anteriormente expressas, fazendo destas seu argumento. Nesse processo em que 
uma conclusão se torna argumento para a conclusão seguinte, a finalidade é também bloquear possíveis objeções de GM. Por exemplo, combinando os conectores $e$ e portanto no início do ato (63), LRB sinaliza que a intervenção formada pelos atos (6366) traz a conclusão das informações expressas na intervenção formada pelos atos (5862):

(58) Zé Dirceu permaneceu preso/ sob minha jurisdição/ (59) inclusive recorri à prisão domiciliar (60) porque achei imprópria/ (61) e concedi a ele indulto com base no decreto/ eeh.. aprovado pela presidente da República/ (62) porque ninguém é melhor nem pior do que ninGUÉM/ (63) e portanto apliquei a ele a lei que vale para todo mundo/ (64) quem decidiu foi o Supremo/ (65) aliás não fui eu/ (66) porque o Supremo tem onze ministros $\backslash$

Ao estabelecer essa relação de argumento, LRB impede que GM levante objeções como: 'Seu julgamento [a aplicação da lei] foi infundado' ou 'O julgamento se fez com base em que decreto?'.

Com esse processo de subordinações retroativas, LRB cria uma hierarquia ou escala entre as informações introduzidas pelas ocorrências de portanto, das quais a mais forte é expressa no ato (76) ("portanto não transfira pra mim. esta parceria que vossa excelência tem com a leniÊNcia em relação à criminalidade do colarinho branco $\backslash \backslash$ '), que traz nova crítica ao comportamento de GM, atribuindo-lhe novamente o papel de ofensor, por adotar uma linha de conduta que LRB avalia como incompatível com o status de ministro do Supremo. No entanto, a crítica recai não mais sobre o estado emocional do interlocutor, como ocorreu nos atos (33-49), mas sobre sua idoneidade.

Porque as relações de discurso impõem restrições sobre o modo como os interlocutores podem participar da interação, as várias relações de argumento estabelecidas por LRB, na intervenção (58-76), têm como efeito a modificação da linha de conduta refutativa que GM vinha adotando desde o início do excerto. No ato (68) ('então não venha/ então não venha/'), o ministro esboça uma refutação, que não conclui, já que, com o ato (67) ('e portanto a maioria entendeu/'), LRB evidencia, seja pelo uso do conector portanto, seja pela entonação ascendente de 'entendeu', que não alcançou a completude de sua intervenção (Burger; Jacquin, 2015). E, após a conclusão da intervenção de LRB, GM, no ato (77) ('[he] imagine \. [he]. imagine \'), elabora uma refutação em que tenta questionar a veracidade das informações expressas pelo interlocutor. Porém, a refutação é tão lacunar e indireta que é malsucedida na tarefa de apontar o comportamento de LRB como desviante e ofensivo. Por isso, a ministra Carmen Lúcia entende sua produção como o momento oportuno para intervir novamente e, numa intervenção metadiscursiva (atos 78-80), interromper a discussão, revelando que, para ela, o comportamento dos ministros é desviante em relação ao comportamento esperado de ministros 'no plenário de um supremo tribunal' (ato 79) e que ambos, portanto, estão agindo de forma ofensiva e colocando em risco as faces e os territórios de todos os participantes da interação, mesmo dos ministros que não tomaram a palavra.

\section{CONSIDERAÇÕES FINAIS}

Na proposta apresentada neste trabalho, as relações de discurso são concebidas como recursos que, ao longo do processo de coordenação de ações, permitem aos 
interlocutores a negociação de imagens identitárias (faces e territórios). Estabelecendo relações de exemplificação, evidência, preparação, concessão, reformulação, explicação etc., o locutor busca elaborar uma intervenção que possa ser avaliada pelo/s interlocutor/es como adequada, seguindo um modo de agir que não viole as expectativas (regras de conduta) que subjazem ao encontro e que, portanto, não seja ofensivo ao/s interlocutor/es. Com as relações de discurso, o locutor tenta, assim, antecipar-se a possíveis objeções do/s interlocutor/es, bloqueando-as e evitando a assunção pelos interlocutores dos papéis de ofensor e ofendido, bem como as implicações negativas que decorrem dessa assunção. Porém, em função do compartilhamento apenas parcial entre os interlocutores das expectativas concernentes ao tipo de interação de que participam, o locutor não tem garantias de que as relações que estabelece serão, de fato, eficazes no bloqueio de objeções, o que faz desse processo de negociação de imagens identitárias por meio das relações de discurso um fenômeno dinâmico e fortemente ancorado na maneira como os interlocutores coordenam suas ações.

Verificou-se a dinamicidade desse processo por meio da análise de excerto de sessão do Superior Tribunal Federal (STF). Nele os interlocutores, ministros Gilmar Mendes e Luís Roberto Barroso, ao estabelecerem relações de discurso, negociam (revelam, reforçam, reavaliam, contestam, modificam) as expectativas de ordem sóciohistórica que sustentam seus comportamentos, avaliam a im/pertinência da linha de conduta que seguem e impõem restrições sobre o modo como devem agir ao longo da interação. O resultado da realização dessas ações foi uma gestão conflituosa e agressiva das imagens identitárias em que, por meio de objeções, cada interlocutor demonstra que a incompletude da intervenção produzida pelo outro constitui uma ofensa, exatamente por contrariar suas expectativas sobre o comportamento esperado em sessões do STF.

Inserida no paradigma interacionista dos estudos da linguagem, a proposta aqui apresentada para o estudo das relações de discurso busca contribuir para uma melhor compreensão do papel dessas relações na dinâmica interacional e no modo como os interlocutores, ao interagirem, mobilizam e re/modelam suas expectativas sobre como agir. Não desconsiderando a importância da dimensão informacional das relações de discurso, dimensão tradicionalmente focalizada pelos estudos sobre articulação textual ou oracional, procuramos evidenciar que as relações contribuem não só para a elaboração de uma intervenção compreensível, mas também para a negociação das imagens identitárias em jogo, desempenhando papel de primeira importância na dimensão ritual (ou dramatúrgica) do discurso.

\section{REFERÊNCIAS}

Bakhtin M. Os gêneros do discurso. In: Bakhtin M. Estética da criação verbal. São Paulo: Martins Fontes; 2003. p. 261-306.

Barros AT, Lemos CRF. Política, pânico moral e mídia: controvérsias sobre os embargos infringentes do escândalo do Mensalão. Opinião Pública. 2018;24(2):291-327.

Bres J, Nowakowska A. Dialogisme: du principe à la matérialité discursive. In: Perrin L. Le sens et ses voix. Metz: Université de Metz; 2006. p. 21-48. 
Bres J, Nowakowska A. "J'exagère?...” Du dialogisme interlocutif. In: Birkelund M, Hansenm MBM, Norén C. L’énonciation dans tous ses états. Berne: Peter Lang; 2008. p. 1-27.

Bres J, Nowakowska A, Sarale JM. Anticipative interlocutive dialogism: sequential patterns and linguistic markers in French. Journal of Pragmatics. 2016;96:80-95.

Bronckart JP. Atividade de linguagem, textos e discursos. Por um interacionismo sócio-discursivo. São Paulo: EDUC; 2007.

Brown P, Levinson S. Politeness. Some universals in language use. Cambridge: Cambridge University Press; 1987.

Brown G, Yule G. Discourse Analysis. Cambridge: Cambridge University Press; 1983.

Burger M. Identités de status, identités de role. Cahiers de linguistique française. 1999;21:35-59.

Burger M. La gestion des activités: pratiques sociales, roles interactionnels et actes de discours. Cahiers de linguistique française. 2004;26:177-196.

Burger M, Jacquin J. La textualisation de l'oral: éléments pour une observation de la construction collaborative de la complétude. In: Adam JM. Faire texte. Frontières textuelles et opérations de textualisation. Besançon: Presses universitaires de Franche-Comté; 2015. p. 277-318.

Clark H. Using language. Cambridge: Cambridge University Press; 1996.

Couper-Kuhlen E, Selting M. Interactional Linguistics: studying language in social interaction. Cambridge: Cambridge University Press; 2018.

Culpeper J. Impoliteness. Using language to cause offense. Cambridge: Cambridge University Press; 2011.

Cunha GX. As relações retóricas e a negociação de faces em debate eleitoral. Confluência. 2015;47:205-238.

Cunha GX. Conectores e processo de negociação: uma proposta discursiva para o estudo dos conectores. Fórum Linguístico. 2017a;14:1699-1716.

Cunha GX. O papel dos conectores na co-construção de imagens identitárias: o uso do mas em debates eleitorais. ALFA. 2017b;61:599-623.

Cunha GX. Estratégias de impolidez como propriedades definidoras de interações polêmicas. Delta. 2019a;35(2):1-28.

Cunha GX. Caracterização e funcionamento da refutação em debate eleitoral. Cadernos de Letras da UFF. 2019b;30(59):147-176.

Cunha GX. Elementos para uma abordagem interacionista das relações de discurso. Linguística. 2020;36(2): 107-129.

Cunha GX. Relações de discurso e completude monológica: o impacto da restrição ritual sobre o estabelecimento das relações interativas. Forma y Función. 2021;34(1):1-24.

Cunha GX, Braga PB. Definindo o comentário metadiscursivo em uma perspectiva interacionista da Análise do Discurso. SCRIPTA. 2018;22:171-188.

Cunha GX, Picinin RVC. As relações de poder em uma abordagem modular da organização do discurso. Filologia e Linguística Portuguesa. 2018;20(1):77-96. 
Cunha GX, Tomazi MM. O uso agressivo da linguagem em uma audiência: uma abordagem discursiva e interacionista para o estudo da im/polidez. Calidoscópio. 2019;17:297-319.

Doury M, Kerbrat-Orecchioni C. La place de l'accord dans l'argumentation polémique: les cas du débat Sarkozy/Royal (2007). A contrario. 2011;16(2):63-87.

Ducrot O. Argumentation rhétorique et argumentation linguistique. In: Doury M, Moirand S. L'argumentation aujourd'hui. Positions théoriques en confrontation. Paris: Presses de la Sorbonne Nouvelle; 2005. p. 17-34.

Ducrot O, et al. Les mots du discours. Paris: Minuit; 1980.

Fávero LL, Andrade MLCVO, Aquino ZGO. Estratégias de construção do texto falado: a correção. In: Kato M. Gramática do Português Falado: convergências. Campinas: Editora da Unicamp; 2002a. p. 359-369.

Fávero LL, Andrade MLCVO, Aquino ZGO. A correção do texto falado: tipos, funções e marcas. In: Neves MHM. Gramática do Português Falado: novos estudos. Campinas: Editora da Unicamp; 2002b. p. $105-142$.

Fávero LL, Andrade MLCVO, Aquino ZGO. Correção. In: Jubran CCAS, Koch IGV. Gramática do português culto falado no Brasil: construção do texto falado. Campinas: Editora da Unicamp; 2006. p. $255-274$.

Filliettaz L. Actions, activités et discours [tese]. Genebra: Faculdade de Letras, Université de Genève; 2000 .

Filliettaz L. L'interaction langagière: un object et une méthode d'analyse en formation des adultes. In: Friedrich J, Castro JCP. Recherches en formation des adultes: un dialogue entre concepts et réalité. Dijon: Éditions Raison et Passions; 2014. p. 127-162.

Filliettaz L. Les ressources interactionnelles de la structuration des activités en contexte éducatif. Bulletin suisse de linguistique appliquée. 2015;101:11-26.

Filliettaz L. La compétence interactionnelle: un instrument de développement pour penser la formation des adultes. Education permanente. 2019;220/221:185-194.

Filliettaz L, Roulet E. The Geneva Model of discourse analysis: an interactionist and modular approach to discourse organization. Discourse Studies. 2002;4(3):369-392.

Filliettaz L, Durand I, Trébert D. Dos processos de figuração às configurações de participação na interação: reflexões relacionais para a formação profissional. In: Cunha GX, Oliveira ALAM. Múltiplas perspectivas do trabalho de face nos estudos da linguagem. Belo Horizonte: FALE/POSLIN/UFMG; 2018. p. 43-70.

Goffman E. Interaction ritual. Essays on face-to-face behavior. New York: Pantheon Books; 1967.

Goffman E. La mise em scène de la vie quotidienne. Les relations em public. Paris: Les Éditions de Minuit; 1973.

Goffman E. Os quadros da experiência social: uma perspectiva de análise. Petrópolis: Vozes; 2012[1986].

Grice HP. Logic and conversation. In: Cole P, Morgan JL. Sintax and semantics. Speech acts. New York: Academic Press; 1975. p. 41-58.

Guimarães E. Texto e argumentação: um estudo de conjunções do português. Campinas: Pontes; 1987. 
Haugh M. Impoliteness and taking offence in initial interactions. Journal of Pragmatics. 2015;86:36-42.

Hilgert JG. Esboço de uma fundamentação teórica para o estudo das atividades de formulação textual. In: Castilho AT. Gramática do Português Falado: abordagens. Campinas: Editora da Unicamp; 2002[1990]. p. 99-118.

Hilgert JG. As paráfrases na construção do texto falado: o caso das paráfrases em relação paradigmática com suas matrizes. In: Koch IGV. Gramática do Português Falado: desenvolvimentos. Campinas: Editora da Unicamp; 2002. p. 143-158.

Hilgert JG. Parafraseamento. In: Jubran CCAS, Koch IGV. Gramática do português culto falado no Brasil: construção do texto falado. Campinas: Editora da Unicamp; 2006. p. 275-300.

Jacquin J. Débattre: l'argumentation et l'identité au coeur d'une pratique verbale. Bruxelles: De Boeck Supérieur; 2014.

Jay T, Janschewitz K. The pragmatics of swearing. Journal of Politeness Research. 2008(4):267-288.

Kerbrat-Orecchioni C. Les interactions verbales. Paris: Armand Colin; 1990.

Kerbrat-Orecchioni C. L’énonciation: de la subjectivité dans le langage. Paris: Armand Colin; 1997.

Kuyumcuyan A. Entre connecteur et modalisateur: à propos de quelques emplois de autant/façon de dire que. Journal of French Language Sudies. 2016;26:29-43.

Ladilova A. Multimodal metaphors of interculturereality. Revista de Estudos da Linguagem. 2020;28(2):917-955.

Laforest M, Vincent D. La qualification péjorative dans tous ses états. Langue Française. 2004;144:5981.

Lakoff R. What you can do with words: politeness, pragmatics and performatives. In: Rogers A, Wall B, Murphy JP. Proceedings of the Texas Conference on performatives, presuppositions and implicatures. Arlington: Center for Applied Linguistics; 1977. p. 94-120.

Langlotz A, Locher MA. (Im)politeness and Emotion. In: Culpeper J, Haugh H, Kádár DZ. The Palgrave handbook of Linguistic (Im)politeness. London: Palgrave Macmillan; 2017. p. 287-322.

Leech G. Principles of Pragmatics. London: Longman; 1983.

Leech G. The pragmatics of politeness. Oxford: Oxford University Press; 2014.

Levinson SC. Activity types and language. In: Drew P, Heritage J. Tlak at work: interaction in institutional settings. Cambridge: Cambridge University Press; 1992. p. 66-100.

Marcuschi LA. A repetição na língua falada como estratégia de formulação textual. In: Koch IGV. Gramática do Português Falado: desenvolvimentos. Campinas: Editora da Unicamp; 2002. p. 105-142.

Moeschler J. Argumentation et conversation. Éléments pour une analyse pragmatique du discours. Paris: Hatier-Credif; 1985.

Moeschler J, Spengler N. La concession ou la réfutation interdite, approches argumentative et conversationnelle. Cahiers de linguistique française. 1982;4:7-36.

Mondada L. La compétence comme dimension située et contingente, localement évaluée par les participants. Bulletin suisse de linguistique appliquée. 2006;84:83-119. 
Mondada L. Contemporary issues in conversation analysis: Embodiment and materiality, multimodality and multisensoriality in social interaction. Journal of Pragmatics. 2019;145:47-62.

Morato EM. A noção de competência no campo da Linguística. In: Signorini I. Situar a língua[gem]. São Paulo: Parábola; 2008. p. 39-66.

Neves MHM. As construções concessivas. In: Neves MHM. Gramática do Português Falado: novos estudos. Campinas: Editora da Unicamp; 1999. p. 545-594.

Pekarek Doehler S. Compétence et langage en action. Bulletin suisse de linguistique appliquée. 2006;84:09-45.

Rinn M. Émotions et discours: l'usage des passions dans la langue. Rennes: Presses universitaires de Rennes; 2008.

Roulet E. Complétude interactive et connecteurs reformulatifs. Cahiers de linguistique française. 1987;8:111-140.

Roulet E. La description de l'organisation du discours. Du dialogue au texte. Paris: Didier; 1999.

Roulet E, et al. L'articulation du discours en français contemporain. Berne: Peter Lang; 1985.

Roulet E, Filliettaz L, Grobet A. Un modèle et un instrument d'analyse de l'organisation du discours. Berne: Peter Lang; 2001.

Schutz A. Sens commun et interprétation scientifique de l'action humaine. In: Schutz A. Le chercheur et le quotidien: phénoménologie des sciences sociales. Paris: Méridiens Klincksieck; 1987. p. 07-63.

Schegloff EA. Sequence organization in interaction: a primer in Conversation Analysis I. Cambridge: Cambridge University Press; 2007.

Schegloff EA, Jefferson G, Sacks H. The preference for self-correction in the organization of repair in conversation. Language. 1977;53(2):361-382.

Vincent D, Heisler T. L'anticipation d'objections: prolepse, concession et réfutation dans la langue spontanée. Revue québécoise de linguistique. 1999;27(1):15-31.

Vion R. La communication verbale: analyse des interactions. Paris: Hachette; 1992.

\section{ANEXO}

\section{Transcrição ${ }^{9}$}

GM: (01) a prova de que falta criatividade ao administrador é o caso do Rio de Janeiro \\(02) gente/ citar o Rio de Janeiro como exemplo/

LRB: (03) devem achar que é Mato Grosso \

GM: (04) não não.. (05) é o Rio de Janeiro mesmo-

LRB: (06) onde tá todo mundo PREso \\

GM: (07) éh ah não (08) no no Rio não estão//

LRB: (09) não não sim (10) aliás nós prendemos/. (11) tem gente que solta \\

GM: (12) veja veja o caso/. (13) solta cumprindo: a Constituição \\(14) quem gosta de prender// (15) vossa excelência quando chegou aqui/.. (16) éh soltou o Zé Dirceu:: \.. [ㄱah] LRB: (17) porque recebeu inDULto do presidente da República \\}

\footnotetext{
${ }^{9}$ No excerto, os interlocutores são referidos pelas siglas: CL (Carmen Lúcia), GM (Gilmar Mendes) e LRB (Luís Roberto Barroso).
} 
GM: (18) não não não (19) vossa excelência disse/. (20) vossa excelência julgou os embargos infringentes/

LRB: (21) absolutamente é mentira/

GM: (22) não:...... (23) vossa excelência dizia que o mensalão/

LRB: (24) é menti/ (25) aliás vossa excelência normalmente não trabalha com a verdade $\backslash$

GM: (26) eh... eh...

LRB: (27) então gostaria de dizer que José Dirceu foi SOLto/

GM: (28) não não/

LRB: (29) por inDULto da presidente da República \\}

GM: (30) vossa excelência julgou\

LRB: (31) não/

GM: (32) vossa excelência julgou (demais)/

LRB: (33) e vossa excelência tá fazendo um comício que não tem nada que ver com extinção de tribunal de contas no CeaRÁ \\

GM: (34) tem $\backslash \backslash$ tem $\operatorname{sim} \backslash \backslash$

LRB: (35) vossa excelência tá queixoso (36) porque perdeu o caso dos precatórios. (37) e tá ocupando tempo do plenário com assunto que NÃO é pertinente/

GM: (38) nós escutamos vossa excelência/

LRB: (39) pra destilar esse Ódio constante que vossa excelência tem. (40) e agora o dirige contra o Rio/.. (41) vossa excelência devia ouvir a última música do Chico Buarque/.. (42) a RAIva é filha do medo e MÃE da covardia \(43) vossa excelência fica destilando ódio o tempo inteiro/ (44) não julga/ (45) não fala coisas racionais articuladas/ (46) sempre fala coisa contra alguém/ (47) tá sempre com ódio de alguém/ (48) tá sempre com raiva de alguém/ (49) use um argumento... o mérito do argumento...

CL: (50) ministros/.. eu pediria que a gente voltasse/ ah voltasse ao julgamento do caso/ por favor $\backslash \backslash$

GM: (51) mas eu vou voltar... vou voltar... (52) só eu só queria lembrar que os embargos infringentes do José Dirceu foram decididos aqui. $\underline{\text { com/ }}$

CL: (53) ministro. se pudesse/

GM: (54) uhn

CL: (55) voltar ao caso do Tribunal de Contas// (56) este. este é o caso em julgamento \\

GM: (57) e se dizia que o mensalão era caso fora da curva/

LRB: (58) Zé Dirceu permaneceu preso/ sob minha jurisdição/ (59) inclusive recorri à prisão domiciliar (60) porque achei imprópria/ (61) e concedi a ele indulto com base no decreto/ eeh.. aprovado pela presidente da República/ (62) porque ninguém é melhor nem pior do que ninGUÉM/ (63) e portanto apliquei a ele a lei que vale para todo mundo/ (64) quem decidiu foi o Supremo/ (65) aliás não fui eu/ (66) porque o Supremo tem onze ministros $\backslash(67)$ e portanto a maioria entendeu/

GM: (68) então não venha/ então não venha/

LRB: (69) que não havia o crime \(70) e depois ele cumpriu a pena/ (71) e só foi SOLto. por inDULto/ (72) e mesmo assim permaneceu preso/ (73) porque estava preso por determinação da $13^{\text {a }}$ Vara Criminal de Curitiba \(74) e agora só está solto (75) porque a SeGUNda turma determinou que ele fosse solto\} (76) portanto não transfira pra mim. esta parceria que vossa excelência tem com a leniÊNcia em relação à criminalidade do colarinho branco $\backslash \backslash$

GM: (77) [he] imagine $\backslash$. [he]. imagine

CL: (78) ministro ministro eu peço por gentileza (79) estamos no plenário de um supremo tribunal (80) e eu gostaria que/. vamos voltar

(Disponível em: https://www.youtube.com/watch?v=ROzEZyf6EAk, TV Justiça.) 